\title{
Prevalence of codon 72 P53 polymorphism in Brazilian women with cervix cancer
}

\author{
Sylvia Michelina Fernandes Brenna ${ }^{1}$, Ismael Dale Cotrin Guerreiro da Silva ${ }^{2}$, Luiz Carlos Zeferino ${ }^{3}$, \\ Julia Pereira $^{2}$, Edson Zachaione Martinez ${ }^{4}$ and Kari Juhani Syrjänen ${ }^{5}$ \\ ${ }^{1}$ Hospital Maternidade Leonor Mendes de Barros, Oncologia Ginecológica, São Paulo, SP, Brazil. \\ ${ }^{2}$ Universidade Federal de São Paulo, Laboratório de Ginecologia Molecular, São Paulo, SP, Brazil. \\ ${ }^{3}$ Universidade Estadual de Campinas, Faculdade de Medicina, Oncologia Ginecológica, Campinas, \\ SP, Brazil. \\ ${ }^{4}$ Universidade de São Paulo, Departamento de Medicina Social, Faculdade de Medicina \\ de Ribeirão Preto, SP, Brazil. \\ ${ }^{5}$ Istituto Superiore di Sanità, Laboratory of Epidemiology and Biostatistics, Cytopathology Unit, Rome, Italy.
}

\begin{abstract}
The p53 codon 72 polymorphism seems to be associated with HPV-carcinogenesis, although controversial data have been reported. A series of Brazilian women with cervix carcinomas were analyzed. Ninety-nine (67\%) of 148 women were found to be homozygous (arg/arg) for the arginine polymorphism, and 49 (33\%) were heterozygous (arg/pro). This polymorphism may be an important determinant of the risk for cervix cancer, but does not seem to be sufficient for carcinogenesis.
\end{abstract}

Key words: p53 polymorphism, codon 72, genetic polymorphism, cervix cancer, human papillomavirus.

Received: October 1, 2003; Accepted: June 3, 2004.

Cancer of the uterine cervix is the second most frequent malignancy in women in developing countries, and responsible for substantial morbidity and mortality worldwide. Almost all cervical carcinomas harbor HPV-DNA sequences, and generally the viral E6 and E7 oncoproteins are expressed in these carcinomas (Walboomers et al., 1999). The E6 and E7 of the oncogenic HPV types bind to $\mathrm{p} 53$ and $\mathrm{pRb}$ proteins, respectively. The fact that the E6 protein from the high-risk HPV can induce degradation of p53 has led to the proposal that this $\mathrm{p} 53$ inactivation pathway could play a key role in cervical carcinogenesis (Syrjänen and Syrjänen, 1999; Brenna and Syrjänen, 2003).

Since its detection in 1987, several studies have linked genetic polymorphism of the p53 codon 72 to carcinogenesis and progression of cervical cancer. A person can carry one of two variations of the $\mathrm{p} 53$ gene in codon 72: either p53 arg or p53 pro. It was suggested that oncoprotein E6 inactivates p53arg(72) more easily than pro(72), bearing some association with the outcome of HPV infections. Indeed, it has been proposed that women

Send correspondence to Sylvia M.F. Brenna. Hospital Maternidade Leonor Mendes de Barros, Oncologia Ginecológica, Secretaria de Saúde do Estado de São Paulo, SP, Brazil. E-mail: brenna.ops@terra.com.br. who are homozygous for p53arg might have a higher susceptibility to the effects of oncogenic HPV types (Storey et al., 1998; Maciag and Villa, 1999, Makni et al., 2000).

The material of the present study consists of 148 Brazilian women diagnosed and treated for HPV-positive invasive cervix cancer (clinical stages I-III) in two clinics: a) Maternity Hospital Leonor Mendes de Barros of the São Paulo State Health Secretariat; and b) Women's Health Care Center of the State University of Campinas. The Ethics Committees of both hospitals approved the research plan, and written informed consent was obtained from all patients. Diagnostic biopsies from all women were available for the study. The samples were fixed in formalin, embedded in paraffin, and processed for $4-\mu \mathrm{m}$-thick HEstained sections. The histological diagnosis of carcinoma was confirmed according to routine procedures.

The demonstration of a codon $72 \mathrm{p} 53$ genetic polymorphism was performed in DNA extracted from paraffin-embedded sections, using the Polymerase Chain Reaction (PCR) technique. In brief, 4- $\mu \mathrm{m}$ sections of the tumor were treated with xylene, ethanol, proteinase $\mathrm{K}$, phenol and chloroform. Pellets were resuspended in milliQ water and stored at $-20^{\circ} \mathrm{C}$. Then, $5 \mu \mathrm{L}$ aliquots of DNA were sub- 
jected to PCR, using Master Mix (Eppendorf, Düsseldorf, Germany) together with the following primers:

ArgF: 5'-TCC CCC TTG CCG TCC CAA -3' bp)

ArgR: 5'-CTG GTG CAG GGG CCA CGC-3' (144

\section{ProF:5'-GCC AGA GGC TGC TCC CCC-3'}

ProR 5'-CGT GCA AGT CAC AGA CTT-3'(177bp)

$\beta$ globin F: 5'-CAA CTT CAT CCA CGT TCA CC-3'

$\beta$ globin R: 5'-GAA GAG CCA AGG ACA GGT AC-3'

PCR was performed in separate tubes for arg, pro alleles, and $\beta$ globin; bands were separated in $2 \%$ lowmelting point agarose stained with ethidium bromide and analyzed using the Kodak EDAS 120 software in order to increase sensitivity. All samples were previously analyzed for $\beta$ globin amplification, in order to check the quality and quantity of DNA. Thermal cycling was accomplished by using a GenAmp PCR System 9700 (Applied Biosystems). The cycling profile, as well as the agarose gel electrophoresis, followed exactly the protocol used by Soulitzis et al. (2000) (Figure 1).

Unconditional logistic regression analysis was used to calculate odds ratios (ORs) as measures of association between $\mathrm{p} 53$ polymorphism and the clinical stage, with respective $95 \%$ confidence intervals (CIs). Confounding control was done by multiple logistic regression models, resulting in adjusted ORs. The statistical analyses were made with the SAS version 8.2 software.

The histological diagnosis of squamous cell carcinoma (SCC) was confirmed in 144 (97\%) and of adenocarcinoma in $4(3 \%)$ of the cases. Distribution according to clinical stage was as follows: $40(27 \%)$ stage I, $49(33 \%)$ stage II, and $59(40 \%)$ stage III. Among the 148 women, 99 (67\%) were homozygous for the arginine polymorphism (arg/arg), 49 (33\%) were heterozygous (arg/pro) and none was homozygous for (pro/pro).

Table 1 shows the distribution of the p53 polymorphism according to the clinical stage. There was no significant difference in the distribution of the polymorphism between the clinical stages. Multiple logistic models containing also the interaction terms evaluated the joint association of polymorphisms with clinical stages, but this analysis did not show evidence suggesting a relationship between the variables and $\mathrm{p} 53$ polymorphism.

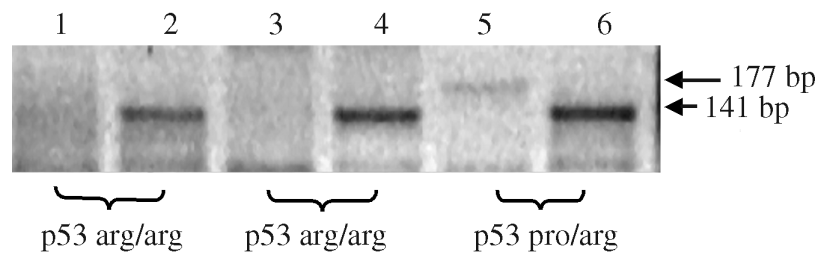

Figure 1 - PCR amplification of the p53 codon 72 arg allele (144 bp) and pro allele (177 bp). Agarose and ethidium bromide, analyzed by Kodak EDAS 120.
Table 1 - Distribution of p53 polymorphism in Brazilian women according to the FIGO stages.

\begin{tabular}{|c|c|c|c|c|c|c|}
\hline \multirow{3}{*}{ Stages } & \multicolumn{4}{|c|}{ p53 polymorphism } & \multirow[b]{3}{*}{$\begin{array}{l}\text { crude OR } \\
(95 \% \mathrm{CI})\end{array}$} & \multirow[b]{3}{*}{$\begin{array}{l}\text { adjusted* OR } \\
\quad(95 \% \mathrm{CI})\end{array}$} \\
\hline & \multicolumn{2}{|c|}{$\arg / \arg$} & \multicolumn{2}{|c|}{ arg/pro } & & \\
\hline & $\mathrm{n}$ & $(\%)$ & $\mathrm{n}$ & $(\%)$ & & \\
\hline I & 27 & (27) & 13 & (26) & Ref & Ref \\
\hline II & 32 & (33) & 17 & (35) & $0.9(0.3-2.2)$ & $0.9(0.3-2.1)$ \\
\hline III & 40 & (40) & 19 & (39) & $1.0(0.4-2.4)$ & $0.9(0.3-2.1)$ \\
\hline Total & 99 & (67) & 49 & (33) & & \\
\hline
\end{tabular}

*Adjusted for the other variables in the Table.

Brazil is a multiracial tropical developing country with high incidence and mortality rates of cervix cancer, 18.32 and 4.58 per 100.000 , respectively (Brasil, 2003). In the general population, a polymorphism in $\mathrm{p} 53$ occurs as a result of a proline to arginine transition at codon 72 of exon 4. There is no accurate information about the frequency of that polymorphism in normal Brazilian women, neither in women with cervix cancer. However, Brazilian authors have previously evaluated 82 cases of oral squamous cell carcinoma and 82 controls with similar population characteristics, but with a different tumor biology. They found a genotype distribution of $37.8 \%$ (31) $\mathrm{arg} / \mathrm{arg}, 54.8 \%$ (45) $\arg / \mathrm{pro}$, and $7.4 \%$ (6) pro/pro in the tumor group, and of $40.2 \%$ (33), $54.8 \%$ (45), and $4.9 \%$ (4), respectively, in the normal population (Drummond et al., 2002).

It can be speculated that the genetic background of the host influences the persistence of HPV infection, which could mediate the genetic susceptibility for cervix cancer. Storey et al. (1998) presented data suggesting that individuals who are homozygous arginine display a higher susceptibility of p53 to degradation by the high-risk HPV E6 in vitro. Furthermore, they found that individuals homozygous for arginine were about seven times more susceptible to HPV-associated cervix carcinoma than heterozygotes.

However, the published data on the prevalence of $\mathrm{p} 53$ polymorphism in cervix cancer patients are controversial. As anticipated, the ethnic group characteristics seem to be an important reason for discrepancies in the frequency of this polymorphism. Thus, the frequency of the arginine allele increases with latitude, while the proline allele shows the opposite effect (Beckman et al., 1994).

In Asian women, the frequency of p53arg was found to be relatively low: $42 \%$ (Baek et al., 2000) and 40\% (Kim et al., 2001) in Korean women; 33\% (Yamashita et al., 1999 ) and 44.8\% (Nishikawa et al., 2000) in Japanese women; $31 \%$ in Hong Kong women (Wong et al., 2000); and $27 \%$ in Indian women (Bhattacharya et al., 2002). Similar results were reported in Southern Europe. In Israel, the frequency was $34.8 \%$ in Jewish women, $30.3 \%$ in North African women, and $10.8 \%$ in those of other origins (Arbel-Alon et al., 2002). The results of two series of obser- 
vations on Italian women were controversial: $34 \%$ (Tenti et al., 2000) and $76.7 \%$ (Zehbe et al., 2001). A number of studies on ethnically diverse groups of patients with cervix cancer from Northern Europe have revealed a higher frequency of p53arg than that observed in Asian and South European women. Thus, the frequency of p53arg observed in white English women was 54\% (Rosenthal et al., 1998) and $69.4 \%$ (Brady et al., 1999), in Dutch women (from the Netherlands) 62\% (van Duin et al., 2000), and in Swedish women $63.9 \%$ (Zehbe et al., 2001).

Similar reports are available on cervical cancer patients from America, suggesting that in South and North America the frequency of p53arg is higher than in Central America. The results of a study carried out in Peruvian women revealed a $50.4 \%$ frequency of p53arg (Klug et al., 2001), and in two series of American women, the figures were $55.9 \%$ (Madeleine et al., 2000) and 67\% (Malcolm et al., 2000), respectively. In Central America, results are available from Mexico, showing a $45 \%$ frequency of p53arg (Suarez-Rincon et al., 2002). Against this background, the $67 \%$ prevalence of the arg/arg polymorphism in Brazilian women seems to be high, but it is still consistent with the American data reported (Madeleine et al., 2000; Malcolm et al., 2000; Klug et al., 2001; Suarez-Rincon et al., 2002).

The controversial data found by the different studies have been attributed to ethnic differences, but other potential confounding factors should be considered as well. These could include the sample size, the source of DNA, and the detection techniques used. Another important reason for these discrepant results could be misclassification of the $\mathrm{p} 53$ polymorphism, due to inter-laboratory variations in protocols, affecting the ability to detect p53 polymorphisms. When the p53 polymorphism was analyzed in three different laboratories, the differences in arg/arg genotype compared to other forms were not significant. After exclusion of the discordant genotype, however, the association of arg/arg p53 with cervix cancer was significant, with an OR $=8.0(95 \%$ CI .3-28.5) (Makni et al., 2000).

In conclusion, such variations reflect the geographic spread of HPVs. The $\mathrm{p} 53$ polymorphism may be one of the important determinants of the risk for cervix carcinoma. However, it does not seem to be sufficient to induce cervix carcinogenesis or to determine the progression of the disease. The role of the genetic susceptibility to HPV infections and cervix cancer merits further investigation.

\section{References}

Arbel-Alon S, Menczer J, Feldman N, Glezerman M, Yeremin L and Friedman E (2002) Codon 72 polymorphism of p53 in Israeli Jewish cervical cancer patients and healthy women. Int J Gynecol Cancer 12:741-744.

Baek WK, Cho JW, Suh S, Suh MH, Shin DH, Cho CH, Lee TS and Cha SD (2000) P53 codon 72 polymorphism and risk of cervical carcinoma in Korean women. J Korean Med Sci 15:65-67.

Beckman G, Birgander R, Själander A, Saha N, Holmberg PA, Kivela A and Beckman L (1994) Is p53 polymorphism maintained by natural selection? Human Hereditary 44:266-270

Bhattacharya P, Duttagupta C and Sengupta S (2002) Proline homozygosity in codon 72 of p53: A risk genotype for human papillomavirus-related cervical cancer in Indian women. Cancer Lett 188:207-11.

Brady CS, Duggan-Keen MF, Davidson JA, Varley JM and Stern PL (1999) Human papillomavirus type 16 E6 variants in cervical carcinoma: Relationship to host genetic factors and clinical parameters. J Gen Virol 80:3233-3240.

Brasil. Ministério da Saúde (2003). Estimativas da Incidência e Mortalidade por Câncer no Brasil. Rio de Janeiro, INCA, http://www.inca.org.br.

Brenna SMF and Syrjänen KJ (2003) Regulation of cell cycle is of key importance in human papillomavirus (HPV)-associated cervical carcinogenesis. São Paulo Med J 121:128-132.

Drummond SN, De Marco L, Pordeus Ide A, Barbosa AA and Gómez RS (2002) TP53 codon 72 polymorphism in oral squamous cell carcinoma. Anticancer Res 22:3379-81.

Kim JW, Roh JW, Park NH, Song YS, Kang SB and Lee HP (2001) Polymorphism of TP53 codon 72 and the risk of cervical cancer among Korean women. Am J Obstet Gynecol 184:55-58.

Klug SJ, Wilmotte R, Santos C, Almonte M, Herrero R, Guerrero I, Caceres E, Peixoto-Guimarães D, Lenoir G, Hainaut P, Walboomers JMM and Muñoz N (2001) TP53 polymorphism, HPV infection, and risk of cervical cancer. Cancer Epidemiol Biomarkers Prev 10:1009-1012.

Maciag PC and Villa LL (1999) Genetic susceptibility to HPV infection and cervical cancer. Braz J Med Biol Res 32:915922.

Madeleine MM, Shera K, Schwartz SM, Daling JR, Galloway DA, Wipf GC, Carter JJ, McKnight B and McDougall JK (2000) The p53 arg72pro polymorphism, human papillomavirus, and invasive squamous cell cervical cancer. Cancer Epidemiol Biomarkers Prev 9:225-227.

Makni H, Franco EL, Kaiano J, Villa LL, Labrecque S, Dudly R, Storey A and Matlashewski G (2000) P53 polymorphism in codon 72 and risk of human papillomavirus-induced cervical cancer: Effect of inter-laboratory variation. Int J Cancer 87:528-533.

Malcolm EK, Baber GB, Boyd JC and Stoler MH (2000) Polymorphism at codon 72 of p53 is not associated with cervical cancer risk. Modern Pathol 13:373-378.

Nishikawa A, Fugimoto T, Akutagawa N, Iwasaki M, Takeuchi M, Fujinaga K and Kudo R (2000) P53 polymorphism (codon-72) has no correlation with the development and the clinical features of cervical cancer. Int J Gynecol Cancer 10:402-407.

Rosenthal AN, Ryan A, Al-Jehani RM, Storey A, Harwood CA and Jacobs IJ (1998) P53 codon 72 polymorphism and risk of cervical cancer in UK. Lancet 352:871-872.

Soulitzis N, Sourvinos G, Sourvinos DN and Spandidos DA (2000) P53 codon 72 polymorphism and its association with bladder cancer. Cancer Lett 179:175-183.

Storey A, Thomas M, Kalita A, Harwwod C, Gadiol D, Mantovani F, Breuer J, Leigh IM, Matlashewski G and 
Banks L (1998) Role of a p53 polymorphism in the development of human papillomavirus-associated cancer. Nature 393:229-34.

Suarez-Rincon AE, Moran-Moguel MC, Montoya-Fuentes H, Allegos-Arreola MP and Sanchez-Corona J (2002) Polymorphism in codon 72 of the 553 gene and cervico-uterine cancer risk in Mexico. Ginecol Obstet Mex 70:344-348.

Syrjänen SM and Syrjänen KJ (1999) New concepts on the role of human papillomavirus in cell cycle regulation. Ann Med $31: 175-187$.

Tenti P, Vesentini N, Spaudo MR, Zappatore R, Migliora P, Carnevali L and Ranzani GN (2000) P53 codon 72 polymorphism does not affect the risk of cervical cancer in patients from Northern Italy. Cancer Epidemiol Biomarkers Prev 9:435-438.

van Duin M, Snijders PJF, Vossen MTM, Klaassen E, Voorhorst F, Verheijen RHM, Helmerhorst TJ, Meijer CJLM and Walboomers (2000) Analysis of human papillomavirus type 16 R6 variants in relation to $\mathrm{p} 53$ codon 72 polymorphism genotypes in cervical carcinogenesis. J Gen Virol 81:317-325.
Walboomers JM, Jacobs MV, Manos MM, Bosh FX, Kummer JA, Shah KV, Snijders PJ, Peto J, Meijer CJ and Munoz N (1999) Human papillomavirus is a necessary cause of invasive cervical cancer worldwide. J Pathol 189:12-19.

Wong YF, Chung TK, Cheung TH, Nobori T, Hamptom GM, Wang VW, Li YF and Chang AM (2000) P53 polymorphism and human papillomavirus infection in Hong Kong women with cervical cancer. Gynecol Obstet Investigation 50:6063.

Yamashita T, Yaginuma Y, Saitoh Y, Kawai K, Kurakane T, Hayashi H and Ishikawa M (1999) Codon 72 polymorphism of $\mathrm{p} 53$ as a risk factor for patients with human papillomavirus-associated squamous intraepithelial lesions and invasive cancer of the uterine cervix. Carcinogenesis 20:1733-1736.

Zehbe I, Voglino G, Wilander E, Delius H, Marongiu A, Edler L, Klimek F, Anderson S and Tommasino M (2001) P53 codon 72 polymorphism and various human papillomavirus 16 E6 genotypes are risk factors for cervical cancer development. Cancer Res 61:608-611.

Associate Editor: Emmanuel Dias Neto 